\title{
Correction to: Assessing local climate vulnerability and winegrowers' adaptive processes in the context of climate change
}

\author{
Etienne Neethling ${ }^{1,2} \cdot$ Théo Petitjean $^{1} \cdot$ Hervé Quénol $^{2} \cdot$ Gérard Barbeau $^{1}$
}

Published online: 28 June 2019

(C) Springer Nature B.V. 2019

\section{Correction to: Mitig Adapt Strateg Glob Change (2017) 22:777-803 https://doi.org/10.1007/s11027-015-9698-0}

The original article unfortunately contained an error.

- Section 3.4.2: Reference "Nicholas and Durham 2012" should have been cited in the last sentence. That is "Using a list of viticultural practices defined beforehand, winegrowers had to organize them in an ascending order, from urgent to low adaptation priority, according to a temporal scale, ranging from short to long term over the twenty-first century (Nicholas and Durham 2012)". This reference is already cited in our published paper.

- Section 4.3.3: First sentence, a small formulation change is needed. That is, the text reading "Winegrowers use physical, or as equally shown by Nicolas and Durham (2012), biological or chemical adaptive responses to manage fungal pathogen risks or outbreaks". Our formulation error may give the impression that like our study, Nicolas and Durham (2012) also presented findings on physical responses, which were not the case in their study.

- Figure $5 \mathrm{~b}$ (the second figure on left): The following methodological reference "Adapted from Nicholas and Durham, 2012" should have been cited. Therefore, reading, "Fig. 5 Based on

The online version of the original article can be found at https://oi.org/10.1007/s11027-015-9698-0

Etienne Neethling

etienne.neethling@angers.inra.fr

1 URVV-INRA, UE1117, UMT Vinitera2, 42 rue Georges Morel, 49071 Beaucouzé, France

2 COSTEL-CNRS, UMR 6554 LETG, Université Rennes 2, Place du Recteur Henri Le Moal, 35043 Rennes, France 
the responses of winegrowers from Saumur Champigny, a the priority of climate change adaptation strategies and $\mathbf{b}$ its schematic representation in the short, medium, and long term over the twenty first century (Adapted from Nicholas and Durham, 2012)". This reference is already cited in our published paper.

The original article has been corrected.

Publisher's note Springer Nature remains neutral with regard to jurisdictional claims in published maps and institutional affiliations. 